\title{
EFEITO DA DEBULHA MECÂNICA NA QUALIDADE DE SEMENTES DE MILHO (ZEA MAYS L.) ${ }^{1}$
}

\author{
CLEVERSON SILVEIRA BORBA, RAMIRO VILELA DE ANDRADE, \\ JOÃO TITO DE AZEVEDO \& ANTONIO CARLOS DE OLIVEIRA ${ }^{2}$
}

\begin{abstract}
RESUMO - Sementes do milho híbrido simples BR 201 fêmea, foram debulhadas com teores de água de $10,0,15,5$ e 22,0\%, utilizando-se uma debulhadora estacionária da marca "Nogueira" modelo BC-80, com o cilindro debulhador nas rotaç̃̃es de 400,500,600 e $700 \mathrm{rpm}$. O experimento foi instalado em 1991, no Centro Nacional de Pesquisa de Milho e Sorgo da EMBRAPA, em Sete Lagoas-MG, Brasil. As sementes foram analisadas quanto ao grau de umidade, porcentagem de danos mecânicos, germinação e vigor. Nas condições em que o trabalho foi realizado, os resultados permitiram concluir que, as melhores velocidades do cilindro debulhador, da debulhadora Nogueira modelo BC 80, para a debulha de sementes do milho híbrido simples BR 201 fêmea, são de 400 e 500 rpm; sementes com 10,0\% de umidade suportam maior velocidade do cilindro debulhador e o vigor das sementes decresce com o aumento da velocidade do cilindro debulhador.
\end{abstract}

Termos para indexação: Dano mecânico, teor de umidade, germinação e vigor.

EFFECT OF MECHANICAL TRESHING ON MAYZE (ZEA MAYS L. ) SEED QUALITY

\begin{abstract}
Corn seeds of a single cross BR-201, were shelled with moisture content of 10,0,15,5 and $22,0 \%$, by using a stationary sheller of brand Nogueira model BC-80, with cilynder speed adjusted to 400 , 500,600 and $700 \mathrm{rpm}$. The seeds were analysed for moisture content, mechanical damage, germination and vigor. The experiment was carried out in 1991 at the "National Maize and Sorghum Research Center" of EMBRAPA in Sete Lagoas, MG. The results allowed us to conclude that the better velocity of the sheller Nogueira model BC 80 for BR 201 single cross female maize were 400 and $500 \mathrm{rpm}$. Seeds with $10,0 \%$ of water content resist more to higher velocity of the sheller. The vigor of seed decrease when increase the speed of the sheller.
\end{abstract}

Index terms: Mechanical damage, moisture content, germination and vigor.

\section{INTRODUÇÃO}

A debulha mecânica é um processo normalmente realizado com alto grau de impacto e extrema abrasividade, ocorrendo danos mecânicos na semente e conseqüentemente morte das sementes ou produção de plântulas anormais, causando queda na qualidade dos lotes de sementes. O processo pode ser agravado quando o teor de água da semente e a rotação do cilindro debulhador são desfavoráveis.

Estudando a relação entre umidade e dano mecânico na debulha de sementes de milho, Bunch (1960) verificou que sementes debulhadas com teores de umidade de 14,0,16,0 e $18,0 \%$ foram menos danificadas que aquelas debulhadas com graus de umidade de $8,0,10,0,12,0$ e $20,0 \%$.

\footnotetext{
${ }^{1}$ Aceito para publicação em 21.06.94.

Trabalho financiado pela FAPEMIG.

${ }^{2}$ Pesquisadores do Centro Nacional de Pesquisa de Milho e Sorgo/EMBRAPA. Caixa Postal 151 - CEP 35701970 - Sete Lagoas, MG.
}

Tatum \& Zuber citados por Moore (1972), após um estudo sobre a germinação do milho sob condições adversas, reportaram que o milho processado com 14,0 e $8,0 \%$ de umidade apresentaram danos mecânicos de 3,0 a 4,0 e de 70,0 a $80,0 \%$ de germinaçao..

Hall \& Johnson (1970) estudando a quebra de sementes de milho, induzida pela debulha mecânica em laboratório, simulando as condições de campo, reportaram que a quebra das sementes aumentou com o aumento da velocidade do cilindro debulhador, obtendo médias gerais de germinação de $41,9,38,8$ e $33,9 \%$ quando ajustou o cilindro debulhador para 400,500 e $600 \mathrm{rpm}$, respectivamente. Também encontrou médias de germinação de 59,2, 68,4, $17,0,27,9$ e $28,8 \%$ para sementes debulhadas com teor de água em $36,0,32,0,29,0,23,0,17,0$ e $10,0 \%$, respectivamente.

Um trabalho realizado por Gregg (1954), demonstrou a influência de diferentes tipos de danos mecânicos na germinação das sementes, aonde sementes com dois furos sobre o embrião, sementes com um furo sobre o embrião, se- 
mentes com um corte no pericarpo do lado do embrião, semente com um corte no pericarpo e faltando parte do endosperma, semente com a ponta (pedicelo) removida e semente sem danificação, apresentaram germinação de 13,0, $26,0,48,0,56,0$ e $79,0 \%$, respectivamente.

Chowdhury \& Buchele (1975) investigando o efeito de parâmetros operacionais de uma debulhadora com cilindro debulhador de pneumático, encontraram alta significância para conteúdo de umidade, pressão do pneumático e velocidade de rotação do cilindro e que o índice de danificação dos grãos aumentou com o aumento no conteúdo de umidade, pressão do pneumático e rotação do cilindro debulhador.

Gomes \& Andrews (1971) verificaram que para três lotes de sementes com 11,7, 23,0 e 40,0\% de danos mecânicos, o teste de germinação não mediu efetivamente a qualidade inicial das sementes. $\mathrm{O}$ "teste de frio" foi mais eficiente na predição do efeito detrimental, dos danos mecânicos no armazenamento potencial das sementes. Verificaram que as sementes danificadas mecanicamente, reduziram drasticamente o vigor e a viabilidade quando armazenadas à $30^{\circ} \mathrm{C}$ e $75,0 \%$ de umidade relativa do ar. Verificaram ainda que quanto maior foi o dano mecânico menor foi a produtividade devido às maiores diferenças na relação do peso de grão/espiga.

Popovic \& Milicevic (1987) encontraram que quando as sementes foram colhidas e debulhadas manualmente; colhidas manualmente e debulhadas com máquina; e colhidas e debulhadas com máquina, os índices de sementes sem danificação foram de $95,0,70,0$ e 47,0\%, respectivamente.

A realização do presente trabalho teve como objetivo, determinar o efeito da velocidade de rotação do cilindro batedor e do grau de umidade, na qualidade das sementes de milho.

\section{MATERIAL E MÉTODOS}

Espigas do milho híbrido simples BR 201 fêmea, foram colhidas manualmente de uma única lavoura, com $22,0,15,5$ e $10,0 \%$ de umidade e debulhadas mecanicamente, utilizando-se uma debulhadora estacionária da marca "Nogueira", modelo BC 80. A debulha foi realizada com velocidades de rotação do cilindro debulhador, do tipo "martelo", ajustado para 400, 500, 600 e 700 rpm. O teor de água foi determinado imediatamente após as debulhas, através do "método da estufa", conforme prescrevem as "Regras para Análise de Sementes" (RAS-1980).

A determinação de dano mecânico foi realizada, utilizando amostras de $100 \mathrm{~g}$ retiradas ao acaso da massa de sementes logo após as operações de debulhas, foram imersas em $100 \mathrm{ml}$ da solução "fast green fcf" (p, p'- Dibenzyldiethyldiamino- $p$ "-hydroxytriphenyl carbinol trisulfonic acid anhydride, Disodium Salt) a $0,1 \%$ de concentração por 24 horas. Após a secagem as sementes foram examinadas visualmente, com auxílio de uma lupa de aumento de 5 vezes e determinado a porcentagem de sementes danificadas. As sementes foram consideradas danificadas quando apresentaram no mínimo algum dos seguintes tipos de danos: semente quebrada, partida, com trincas no embrião e pequenos estragos superficiais.

A germinação foi determinada de acordo com o teste prescrito pelas "RAS" e o vigor foi avaliado pelo teste de "envelhecimento acelerado", conforme preconizado por Tao, 1979.

Os experimentos foram conduzidos no Laboratório de Análise de Sementes do Centro Nacional de Pesquisa de Milho e Sorgo em Sete Lagoas MG utilizando o delineamento experimental inteiramente casualizado, com quatro repetições sendo os tratamentos constituidos de um fatorial $4 \times 3$, ou seja, quatro velocidades de rotação do cilindro debulhador (400, 500, 600 e $600 \mathrm{rpm})$ e três niveis de umidade da semente $(22,0,15,5$ e $10,0 \%)$.

\section{RESULTADOS E DISCUSSÃO}

A análise estatística revelou um efeito significativo, ao nível de $1 \%$ de probabilidade, para o tratamento teor de água, na percentagem de danos mecânicos e de germinação. Também houve um efeito significativo, ao nível de $1 \%$ de probabilidade, para o tratamento velocidade do cilindro debulhador na percentagem de dano mecânico. Ainda foi observado um efeito significativo, ao nível de $5 \%$ de probabilidade para a interação dos tratamentos teor de água $\mathrm{x}$ velocidade do cilindro debulhador no vigor.

$\mathrm{Na}$ Tabela 1 pode ser observado que a percentagem média de danos $(16,9 \%)$ ocorreu nas sementes debulhadas com $10,0 \%$ de umidade, diferindo significativamente dos percentuais de danos ocorridos quando as sementes foram debulhadas com 15,5 e $22,0 \%$ de umidade $(45,4$ e $43,5 \%$, respectivamente).

As sementes debulhadas com as velocidades do cilindro debulhador a 400 e $500 \mathrm{rpm}$, apresentaram dentro de cada nível de umidade estudado, percentuais de danos mecânicos significativamente menores que aqueles ocorridos quando as sementes foram debulhadas com as demais velocidades do cilindro debulhador (Tabela 1).

As debulhas realizadas com a velocidade do cilindro debulhador a $600 \mathrm{rpm}$, provocaram $46,6,48,3$ e $21,8 \%$ de danos mecânicos, nas sementes debulhadas com 22.0, 15,5 e $10,0 \%$ de umidade, respectivamente. Nos diferentes níveis de umidade, os danos mecânicos foram sempre maior quando as sementes foram debulhadas à $700 \mathrm{rpm}$.

Na Tabela 1 também pode ser observado que não houve diferença significativa na germinação das sementes de- 
bulhadas com as diferentes velocidades do cilindro debulhador dentro de cada nível de umidade.

TABELA 1. Efeito do grau de umidade e da velocidade de rotação do cilindro debulhador da debulhadora Nogueira modelo BC-80, sobre os danos mecânicos, germinação e vigor de sementes de milho. CNPMS. Sete Lagoas, MG. 1993.

\begin{tabular}{|c|c|c|c|c|}
\hline $\begin{array}{c}\text { Umidade } \\
\text { das sementes } \\
(\%)\end{array}$ & $\begin{array}{l}\text { Velocidade } \\
\text { do cilindro } \\
\text { debulhador }\end{array}$ & $\begin{array}{c}\text { Danos } \\
\text { mecânicos } \\
(\%)\end{array}$ & $\begin{array}{l}\text { Germi- } \\
\text { ção } \\
(\%)\end{array}$ & $\begin{array}{c}\text { Vigor } \\
(\%)\end{array}$ \\
\hline & 400 RPM $^{* *}$ & $35,0 \mathrm{c}$ & $84,8 \mathrm{a}$ & $75,0 \mathrm{aB}$ \\
\hline \multirow[t]{3}{*}{22,0} & 500 RPM & $38,3 \mathrm{c}$ & $83,3 \mathrm{a}$ & $76,5 \mathrm{aB}$ \\
\hline & 600 RPM & $46,6 \mathrm{~b}$ & $84,5 \mathrm{a}$ & $76,8 \mathrm{aC}$ \\
\hline & 700 RPM & $54,2 \mathrm{a}$ & 82,0 a & $71,0 \mathrm{bB}$ \\
\hline \multirow[t]{2}{*}{ Médias } & & 43,5 & 83,6 & 74,8 \\
\hline & 400 RPM & $37,6 \mathrm{c}$ & $81,0 \mathrm{a}$ & $77,3 \mathrm{aB}$ \\
\hline \multirow[t]{3}{*}{15,5} & 500 RPM & $40,8 \mathrm{c}$ & 83,3 a & $77,0 \mathrm{aB}$ \\
\hline & 600 RPM & $48,3 \mathrm{~b}$ & 80,0 a & $68,0 \mathrm{bB}$ \\
\hline & 700 RPM & $55,0 \mathrm{a}$ & $80,3 \mathrm{a}$ & $70,0 \mathrm{bB}$ \\
\hline \multirow[t]{2}{*}{ Médias } & & 45,4 & 81,1 & 73,1 \\
\hline & 400 RPM & $7,4 \mathrm{c}$ & $87,8 \mathrm{a}$ & $86,0 \mathrm{aA}$ \\
\hline \multirow[t]{3}{*}{10,0} & 500 RPM & $7,1 \mathrm{c}$ & 86,0 a & 84,3 aA \\
\hline & 600 RPM & $21,8 \mathrm{~b}$ & 83,5 a & $80,3 \mathrm{bA}$ \\
\hline & 700 RPM & $31,4 \mathrm{a}$ & 85,3 a & $75,8 \mathrm{cA}$ \\
\hline Médias & & 16,9 & 85,6 & 81,6 \\
\hline
\end{tabular}

* Sementes que apresentaram no mínimo alguns dos seguintes defeitos: semente quebrada, partidas e/ou com pequenos estragos superficiais.

** $\mathrm{RPM}=$ Rotação por minuto.

Obs.: Médias seguidas de mesma letra, minúsculas dentro de cada grau de umidade e maiúsculas dentro de cada velocidade do cilindro debulhador, não se diferem significativamente, ao nível de $5 \%$ de probabilidade pelo teste de Tukey.

Os percentuais médios de germinação de 83,6 e 85,6 , verificados nos níveis 22,0 e $10,0 \%$ de umidade, não diferiram entre si, ficando evidente que a germinação não foi afetada pelos danos causados nas sementes, provavelmente pelo fato de que mais de $94,0 \%$ dos danos observados em todos os casos, foram apenas de pequenos estragos superficiais.

Em relação ao vigor, independentemente da umidade das sementes, as velocidades de 400 e $500 \mathrm{rpm}$ proporcionaram os maiores percentuais de vigor, os quais diferiram significativamente dos percentuais apresentados pelas demais velocidades, com exceção da velocidade de $600 \mathrm{rpm}$ no nível de $22,0 \%$ de umidade (Tabela 1 ). Resultados semelhantes foram encontrados por Hall e Johnson (1970), com a diferenca que a qualidade foi aferida em termos de germinação, mas por outro lado contrastaram com os resultados encontrados por Bunch (1960) e os de Tatum e Zuber citados por Moore (1972), provavelmente, devido aos teores de água de alguns níveis de debulha, terem sido diferen- tes dos utilizados por aqueles autores e dos utilizados neste trabalho.

Verificou-se ainda que as sementes com $10,0 \%$ de umidade, ponto onde houve menor dano, apresentou-se com percentuais de vigor significativamente maiores em todas as velocidades de debulha, evidenciando-se a correlação negativa entre dano e vigor das sementes $(r=-0,92)$.

\section{CONCLUSÕES}

Nas condições em que o trabalho foi realizado, os resultados permitiram chegar as seguintes conclusões:

As melhores velocidades do cilindro debulhador, da debulhadora Nogueira modelo BC 80, para a debulha de sementes do milho híbrido BR 201 fêmea, são de $400 \mathrm{rpm}$ e $500 \mathrm{rpm}$.

Sementes com $10 \%$ de umidade suportam maior velocidade do cilindro debulhador, e o vigor das' sementes, decresce com o aumento da velocidade do cilindro debulhador.

\section{REFERÊNCIAS}

BRASIL, Ministério da Agricultura. Regras para Análise de Sementes. Brasília, MA-SNAD-LANARV, 1980.188 p.

BUNCH, H. D. Relationship between moisture content of seed and mechanical damage in seed conveying. Seed World, 86:14-17, 1960.

CHOWDHURY, M. H. \& BUCHELE W. F. Effects of the operating parameters of the rubber roller sheller. Transactions of the ASAE, 18 (3):482-490, 1975.

GOMEZ, F. \& ANDREWS, C. H. Influence of mechanical injury on seed corn quality. Agronomy Abstract, New York, N. Y.p.43. 1971.

GREGG,R. Rough Handling Kills seeds. Seedsmen's Digest, 5: $12,1954$.

HALL, E. G. \& JOHNSON, W. H. Kernel crackage induced by mechanical shelling. Transactions of the ASAE, 13 (1): 51-55, 1970.

MOORE, R. P. Effect of Mechanical Injuries on Viability. In: Roberts, E. H. ed. Viability of seeds. Syracuse University Press. p.94-113, 1972

POPOVIC, R. \& MILICEVIC, M. Effect of processing on pericarp injuries in maize seeds. Informatsionnyil Byulleten po kukuruze. Inst. za kukuruz. Zemun Polje, Belgrado, Yugoslávia, 6:257-268. 1987.

TAO, KAR-LING J. An evaluation of alternative methods of accelerated aging seed vigor test for soybeans. J. Seed Technol, 3:30-40, 1979. 